\title{
Performance Analysis of Target Information Recognition System for Agricultural Robots
}

\author{
Yun Ji, Chongqing Vocational College of Electronic Engineering, China \\ Rajeev Kumar, Chitkara University Institute of Engineering and Technology, India \\ (iD) https://orcid.org/0000-0001-7189-3836 \\ Daljeet Singh, Lovely Professional University, India \\ Maninder Singh, Chitkara University Institute of Engineering and Technology, India
}

\begin{abstract}
In this paper, an agricultural robot vision system is proposed for two typical environments - farmland and orchard-combined with weeding between crops. The system includes orchard production monitoring and prediction tasks, the target information recognition approach, and visual servo decision making. The results obtained from the proposed system show that using the region combination features of image $2 \mathrm{D}$ histogram as the decision-making basis, the accurate and rapid indirect identification and positioning of crop seedlings can be accomplished while skipping the complex process of accurately identifying crops and weeds. The algorithm performs reasonably good as the time of target recognition in the prototype system is found to be less than $16 \mathrm{~ms}$, and the average accurate recognition rate of $97.43 \%$ is achieved. The benefits of the proposed system are the continuous improvement of the quality of agricultural products, the rise of production efficiency, and the increase of economic benefits.
\end{abstract}

\section{KEYWORDS}

Agricultural Robot, Information Acquisition, Machine Vision

\section{INTRODUCTION}

With the rapid development of rural urbanization in China, the mode of agricultural production and operation is advancing with the times. From the traditional family-style scattered, rough production, to the large farmers or rural cooperatives of the scale model, intensive production mode. Agricultural production and management professional companies, agricultural cooperatives, large orchards, family farms came into being, and the benefits of this transformation are the continuous improvement of the quality of agricultural products, the rise of production efficiency and the increase of economic benefits (Chanak et al, 2020; Hasan et al, 2020; Tanigaki et al., 2008).

The tasks involved in monitoring the output of orchard products are labor intensive. Farmers frequently monitor the orchard products to check their conditions, growth and possible damage caused due to pests and insects. Such monitoring is mostly performed by farmers manually. This process is very time consuming and requires labor. To solve this problem, robots have been used to increase the 
productivity of farms. This results in automating different tasks which saves time and energy (Rathee et al. 2020; Sharma et al. 2019; Kour and Arora, 2020). Working in this direction, in this paper, a system is proposed for monitoring and estimating the output of weeding robots and orchard products. For this task, two typical representative operating environments have been chosen i.e. orchard and farmland. The most common fruits and vegetables in the market are apple and lettuce and therefore, both of them are chosen in this study.

In order to accomplish this task, the information recognition and acquisition methods and visual servo control decision-making are utilized based on the color difference between the lettuce and background. Weeding technology is an option in this task but weeding technology among seedlings has high requirements for real-time information acquisition. Also, it is observed that the 3D space object technology also faces difficulties in differentiating the background from the fruit tree images. The background colors of green and green branches and leaves used by apple are similar. The output monitoring and prediction of apple products can be analyzed offline, so the real-time requirement of information acquisition is not very high. Considering the different acquisition methods and tasks of the two kinds of image information, the visual servo system is used to control the weeding to avoid the seedlings between crops (Rathee et al. 2019). The optimal framing strategy of the active visual servo is used to monitor and estimate the output of orchard products, to reduce the impact of branches and leaves on the operation. This provides a scientific method and basis for the research of robot visual servo system which will face two different working environments (De-An et al, 2011; Zhao et al., 2016; Zhang et al. 2020).

The main contribution of the paper is to solve the problems of vision servo system of the agricultural robot. The construction of the visual system in the face of different dimensions of background is studied. An algorithm for accurate target recognition, positioning and segmentation of background is designed and analyzed. Finally, the control and decision-making of visual servo are studied and explained. Results presented for the proposed system show promising improvements from existing state of the art works. The rest of the paper is organized as follows: Section 2 gives the literature review related to the proposed work. The system design method is explained in Section 3. Results and their analysis is provided in Section 4. Finally, Section 5 holds the conclusion of the proposed work.

\section{LITERATURE REVIEW}

Huirong et al. (2005) designed the visual information acquisition and servo control system of the Luffa picking robot including two sets of cameras. Based on the difference of water content between Luffa cylindrical and other objects, the spectral characteristics of Luffa cylindrical in greenhouse were studied, and the preliminary spectral reflection band to distinguish fruits and vegetables from background was finally found. The robot used to complete the operation can walk along the track, and a group of cameras of the robot can be separated from it, work alone along the track, take images of luffa and judge whether it can be picked. The Luffa waiting for picking is received by the robot and then moved to the work area through the track, expand the manipulator, and then through the second group of cameras on the manipulator to take its background image for precise positioning, and finally complete the picking operation through the control system. The experimental results show that the success rate of the agricultural robot is about 76.5\%. Devetak et al. (2019) designed and built a robot vision system for grape picking in Greenhouse Based on double stereo vision technology. The agricultural robot moves along the direction of the grape rack, takes the grape image and judges whether it is mature through the dual vision system in real-time. If the grape is to be picked, the system will automatically calculate its spatial position and send instructions to the manipulator to move it to the working area, and then the camera at the end of the mechanical arm will take close-up pictures to provide accurate position. The experimental results show that the success rate of grape picking by robot vision system based on double stereo vision technology is about $77 \%$ without obstacles. 
Thalengala et al. (2018) developed a vision recognition system and servo control system for pesticide spraying robots to spray herbicides at fixed points in the field. The vision recognition and servo control system is mainly composed of nozzle controller, GPS, directional speed sensor, computer, vision system of multiple cameras, etc. The system can not only acquire the information of single plant and control the weed in real-time but also can recognize the field image.

Yiman (2018) designed a visual servo control system for high-low gap spraying agricultural weeding robot. The agricultural robot is supported by a group of wheels that can be lifted and lowered. A camera is placed under the robot body to capture the image information of seedlings and grasses. The visual servo system analyzes the color difference in the image and extracts the weeds from the background image, weeds are removed by mechanical arm and weeding pesticides are sprayed on the incision. In order to produce a robot for picking Luffa,

A crawler mobile platform with a binocular vision system and vision recognition and positioning system based on dual stereo vision technology was designed in (Purnama et al., 2020; Jani et al. 2019). When walking between Luffa frames, real-time pictures were taken, and the specific location of Luffa was determined by spectral reflection characteristics of Luffa. Zhao et al. (2020) designed a vision system for robots spraying pesticides in greenhouse to detect the disease of crops. Agricultural robot is composed of sprinkler head, disease information diagnosis system, mechanical arm system and suspended mobile platform. The mobile platform is suspended in the air orbit and stops automatically when the Luffa yield is high. The mechanical arm is suspended under the mobile platform to cooperate with the sprinkler head. The vision system of the robot consists of two cameras. The pictures taken are used to analyze the condition of luffa and work out the solution (Shariski et al. 2020; Khanam et al 2019).

The use of IOT based techniques in agriculture is recently studied by many authors (Zhao et al. 2020; Tang et al. 2020; Hu et al. 2020). Peppes (2020) in his study emphasized on the role of drones in the 4th agricultural revolution. Chauhan et al. (2020) have studied the plant diseases using deep learning, big data, and IOT. The challenges and prospects of smart agriculture are summarized by Yang et al. (2020).

\section{SYSTEM DESIGN METHOD}

\subsection{Composition of Vision Servo System of Weeding Robot}

Aiming at the problem of clearing weeds between plants by physical means in greenhouse vegetables, this paper studies a mechanical weeding robot system based on mechanical vision. The system model and experimental prototype are shown in Fig. 1. This weeding robot system is composed of a robot vision system, hoe unit between trees, speed measuring wheel, header lateral movement and guiding mechanism, front weeding robot body, header and tractor power mobile platform (Yanying et al., 2019).

The visual servo system is mainly composed of an embedded controller, robot lateral displacement sensor, tractor forward speed sensor, computer, hoe speed sensor, hoe angle sensor, visual image acquisition system, etc. The vision image acquisition system is composed of multiple cameras and image acquisition cards. The camera is installed in front of the weeding robot and forms an angle with the ground to a certain extent. Then, the image acquisition card is transformed into a picture, which is transmitted to the computer by wireless, and computer detection software is used to identify the seedlings and weeds. Fig. 2 shows a visual image processing system.

Because the vision system has two tasks to accomplish: acquiring the position of the individual target and navigating the robot forward, the camera must be placed in front of the robot, as shown in Figure 3. However, the robot also has a visual blind area, because the rotation axis of the hoe is limited by the robot body mechanism, which causes it to be located outside the visual field of view, so that the seedlings cannot be found for a while, resulting in a state similar to being lost. 


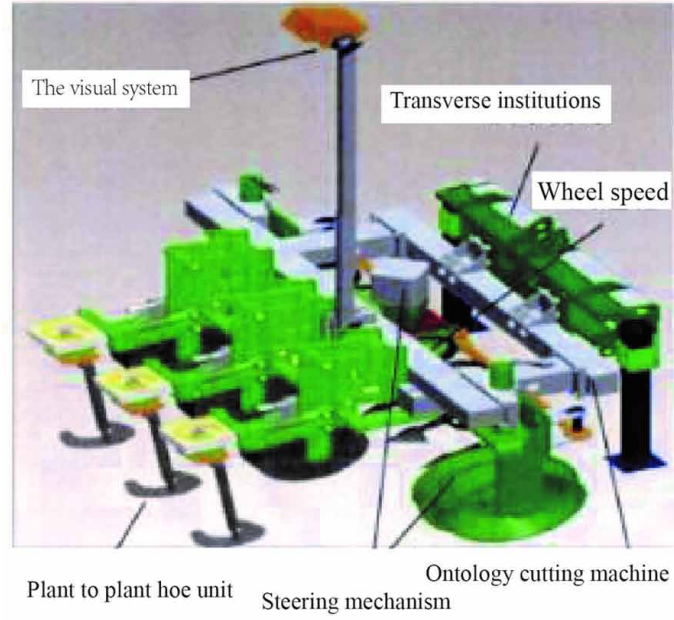

(a)Model of inter-plant weeding robot

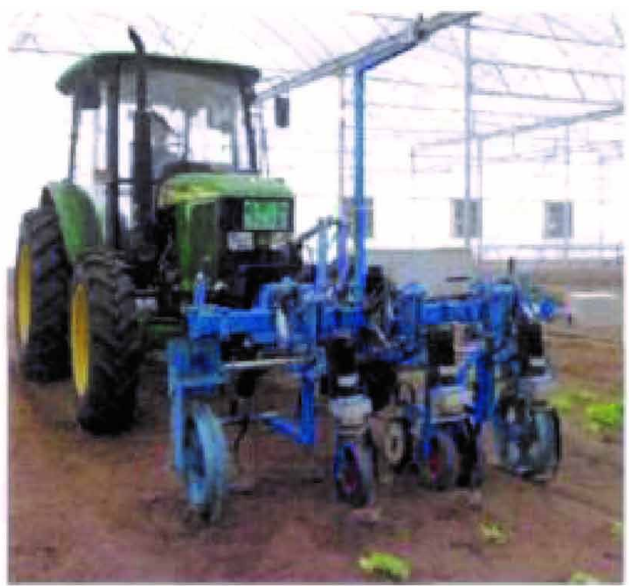

(b) Experimental prototype of inter-plant weeding robot

Figure 2. Composition of the visual image processing system
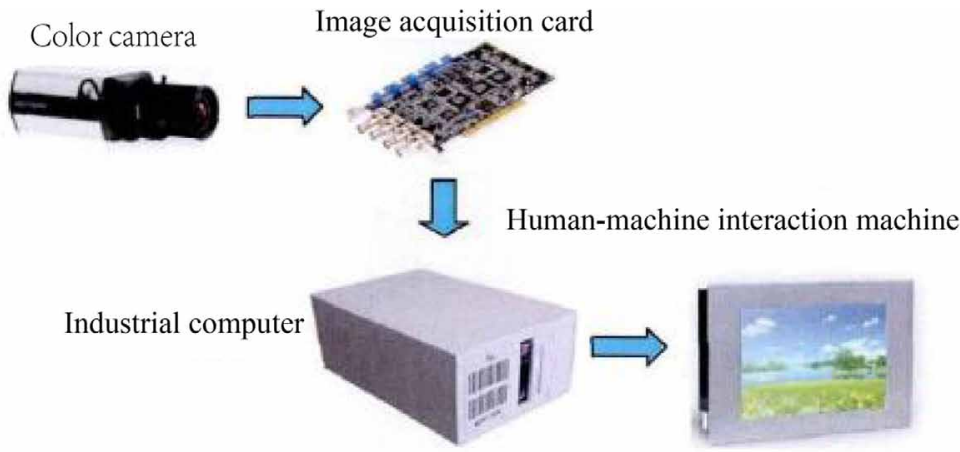

\subsection{Control Decision of Visual Servo}

The hoe knife is shown in Figure 4. When the hoe knife is located at a, it is the initial state when the robot starts to work; when the robot completes the operation, the hoe will start to rotate along its central axis, and when passing through two crops, it will just complete a circle, so that the edge of the hoe blade is well aligned with the seedlings, that is, the position state of B. When the hoe passes through adjacent crops, the blade of the hoe will clear the weeds around the crops. According to the operating principle, according to the distance between plants, the rotation speed of hoe can be controlled, that is, if the distance is too large, the rotation speed will be reduced, otherwise, the rotation speed will be increased.

It can be seen that the individual plant is the reference for the robot to complete the operation. In the process of completing the operation, the forward robot and the fixed plant form relative motion. To ensure that the robot can complete the operation along the correct trajectory, the reference coordinates need to be updated continuously by the visual servo system. 
Figure 3. Visual servo control system

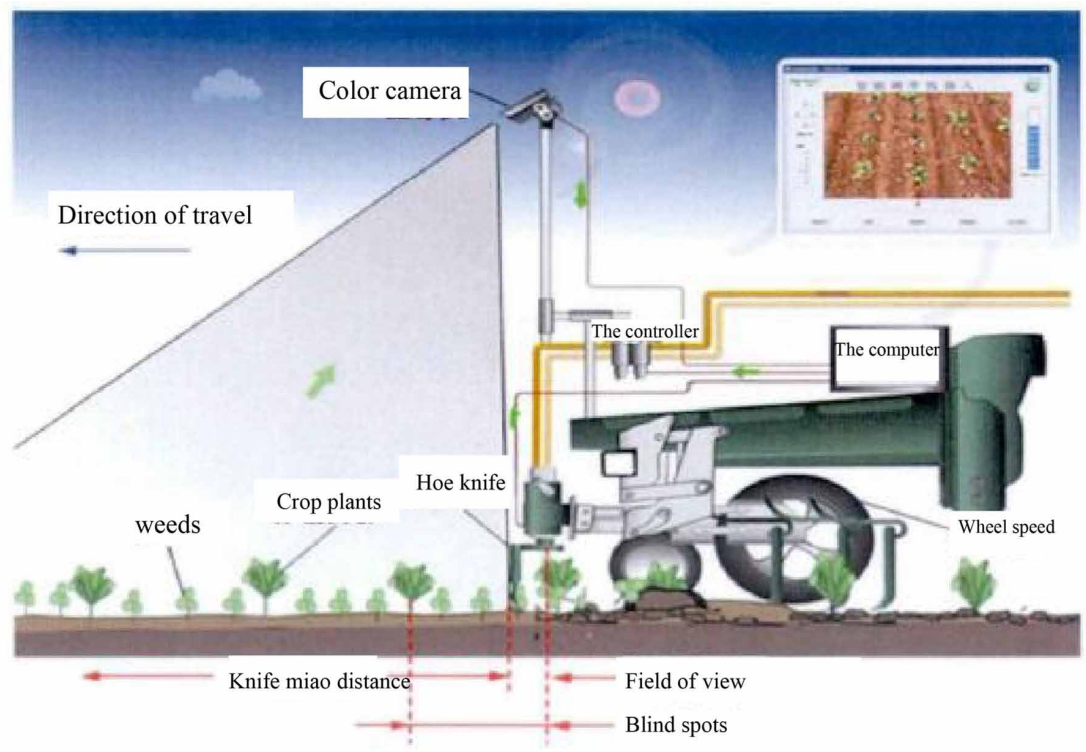

Figure 4. The movement track of hoe and the graph of each movement node among plants

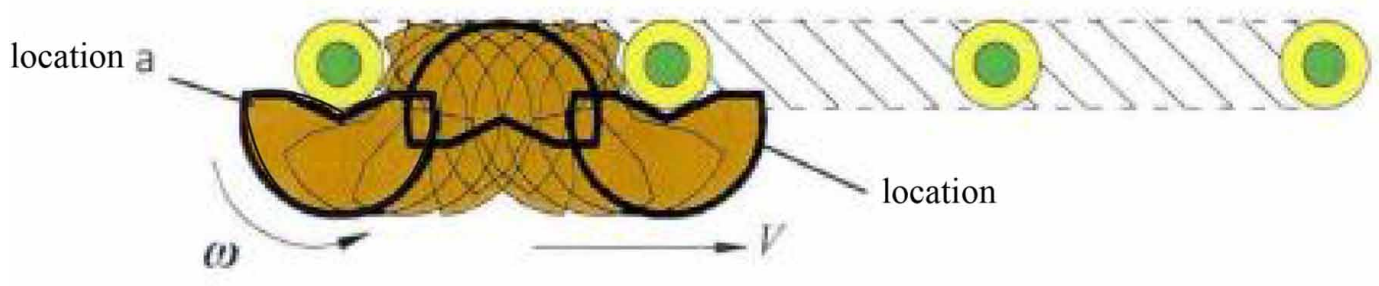

Miao area between

Suppose that the distance between the two plants is D and the hoe rotates $360^{\circ}$ when the agricultural robot is moving at the speed of $\mathrm{V}_{\mathrm{f}}$. The rotation speed of the hoe should be kept as follows: if $\mathrm{V}_{\mathrm{f}}$ is constant, the distance between two plants remains unchanged, and the standard plant spacing $\mathrm{D}_{0}$

$$
\omega=360^{\circ} \cdot V_{f} / d_{0}
$$

Assuming that the hoe is between position a and position B, the angular displacement of the hoe is $\theta$, the distance between the axis of the hoe and the next crop is 1, and the movement speed of the agricultural robot is $\mathrm{V}$, then the rotation speed of the hoe can be calculated as follows:

$\omega=\left(360^{\circ}-\theta\right) \cdot V / L$ 
To know the distance between (2) and (V), if the rotation speed of the three adjacent crops is changed in real-time, then the operation can be completed by changing the rotation speed of the three adjacent robots. The angle detector installed on the handle of the hoe can get $\theta$, and the wheel speed detector can obtain the velocity v. the distance L between the hoe and the next crop can be calculated by the robot vision system. The visual servo decision diagram is shown in Figure 5

Because the rotation axis of hoe is limited by the robot body mechanism, it is located outside the visual field of view, so that the seedlings cannot be found for a while, resulting in a state similar to being lost. At this time, the position of the seedlings cannot be detected by the vision detection system.

As shown in Figure 6, if the length of the blind area is $\mathrm{m}$, and there are seedlings within the field of view, and the visual system accountant calculates that the position of the seedling is $\mathrm{s}$, then the relative distance between the hoe and the seedling is:

$\mathrm{L}=\mathrm{s}+\mathrm{m}$

When the seedlings move out from the lower edge of the field of view, that is to say, they enter the visual blind area. At this time, the robot's speed measuring wheel and its speed measuring device

Figure 5. Visual servo decision diagram

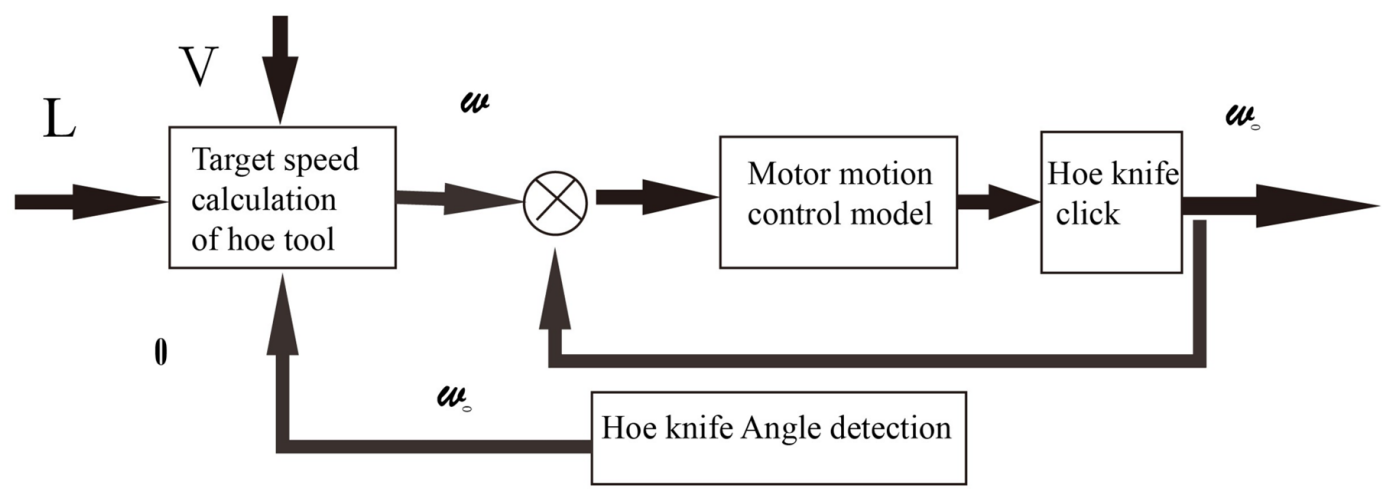

Figure 6. Visual blind area map

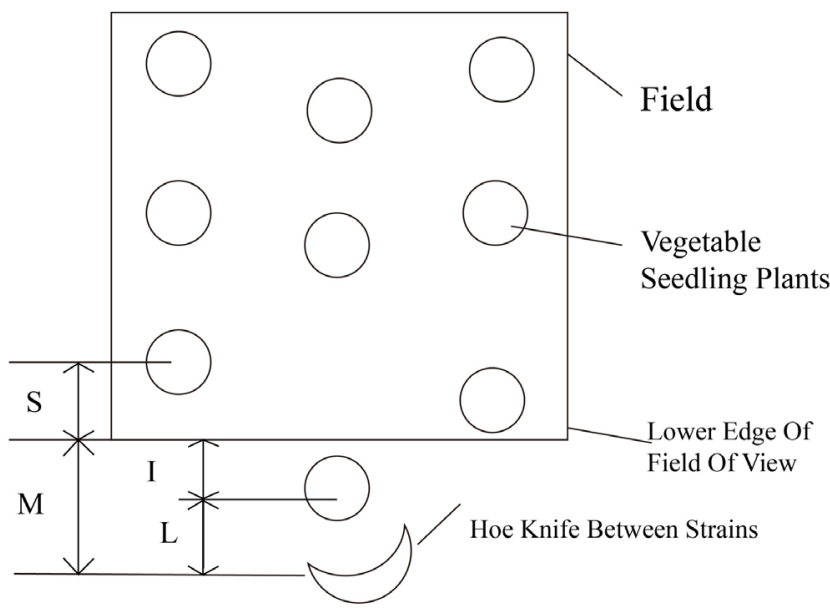


can be used to calculate the robot's walking length in the time when the reference seedling moves out of the field of view to replace the distance $L$ of the reference seedling relative to the hoe knife in this period of time until the seedling position coincides with the HOE's centroid:

$l=\int V \cdot d t$

Then the relative distance between the hoe and the seedling is as follows:

$\mathrm{L}=\mathrm{m}-\mathrm{l}$

\section{RESULT ANALYSIS}

To determine the precision of the weeding robot under the visual servo control system, the research team planted several areas of lettuce in Haimen station of China Agricultural University and selected three areas to study the experiment. Three rows of lettuce were planted in each area, with a horizontal spacing of $60 \mathrm{~cm}$, a vertical minimum spacing of 33, a maximum plant spacing of 70, and an average plant spacing of $474 \mathrm{~cm}$. The length of each lettuce growing area is $60 \mathrm{~m}$. During the test, the first and second blocks are divided into three sections for statistics, which are recorded as test sections $1-1,1-2,1-3,2-1,2-2,2-3$, and the third area as the whole test section is recorded as test section 3 .

Weeding tests will be carried out on the 7th and 14th days after moving to lettuce. The test system used is shown in Figure 1. The camera should be located $1.8 \mathrm{~m}$ above the ground. Generally, the weeding test of lettuce should be started on the 7th day after transplanting, because lettuce has almost grown 4-5 leaves, and many weeds begin to sprout in the field, as shown in Fig. 7, so weeding is better at this time.

On the 7th day after the lettuce transplanting in the first area, the weeding robot carried out a weeding test at the speed of $0.8 \mathrm{kmmh}$ and $1.0 \mathrm{kmmh}$ respectively, and finally carried out weeding at the speed of $1.8 \mathrm{kmmh}$

Weeding and weeding were carried out in the field for the first time on day 3 and day 3 . However, the first planting area was not recorded at the same time on day 3. It can be seen from the figure that the weeds in the first area are significantly less than those in the second and third regions, and their growth is relatively small.

Figure 7. Growth of seedlings and weeds at 7 days after transplanting

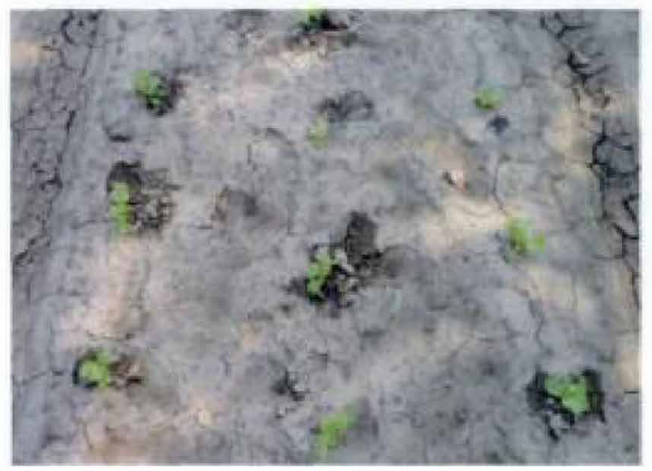

(a)Looks like the lettuce

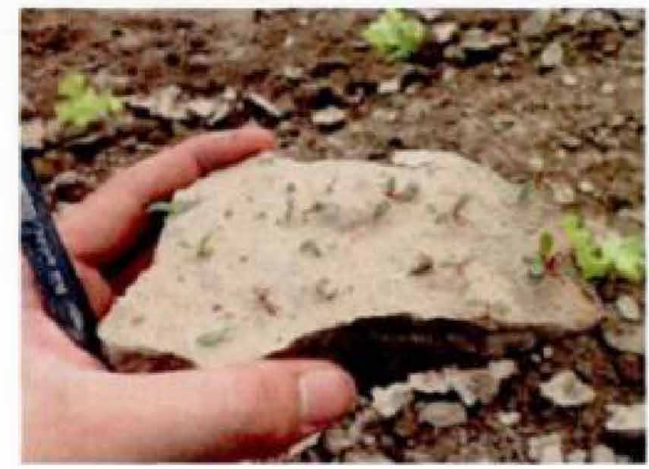

(b)Looks like the weeds 
Table 1. Statistics of weeding experiment 7 days after transplanting

\begin{tabular}{|c|c|c|c|c|}
\hline Test lot No & $\begin{array}{c}\text { Travel speed } \\
\text { kmmh }\end{array}$ & $\begin{array}{c}\text { Total number of } \\
\text { seedlings }\end{array}$ & $\begin{array}{c}\text { Number of injured } \\
\text { seedlings }\end{array}$ & Injury rate\% \\
\hline $1-1$ & 0.8 & 139 & 2 & 1.44 \\
\hline $1-2$ & 1 & 130 & 2 & 1.54 \\
\hline $1-3$ & 1.4 & 135 & 4 & 2.96 \\
\hline $2-1$ & 1.8 & 404 & 14 & 3.47 \\
\hline $2-2$ & 2 & 140 & 1 & 1.42 \\
\hline $2-3$ & 2.2 & 144 & 3 & 1.45 \\
\hline 3 & 2.5 & 210 & 4 & 1.61 \\
\hline average value & & 186 (plant times) & 30 & 1.98 \\
\hline
\end{tabular}

Figure 8. Weed growth 14 days after transplanting

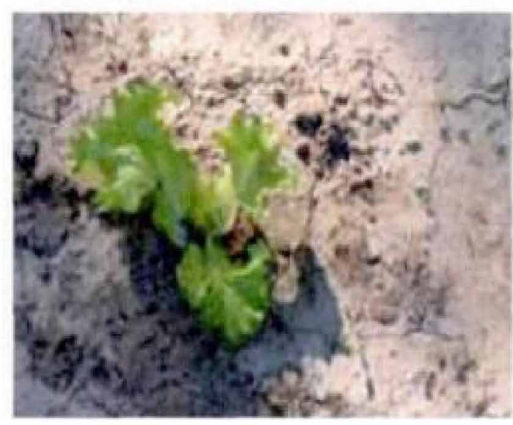

(a)The first field

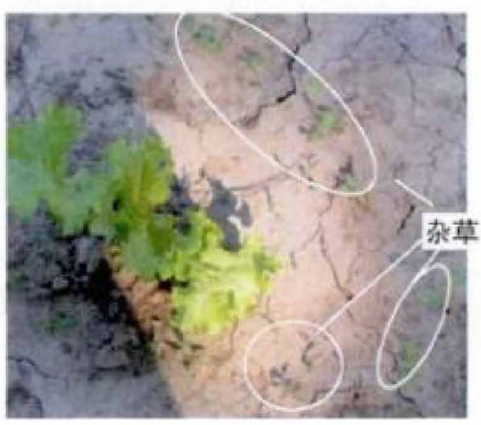

(b)The second and third beds

The weeding robot carries out weeding experiments on lettuce transplanted in the first and second regions at the traveling speeds of $0.8 \mathrm{kmmh}, 1.0 \mathrm{kmmh}, 1.4 \mathrm{kmmh}, 1.8 \mathrm{kmmh}, 2.0 \mathrm{kmmh}$, and $2.2 \mathrm{kmmh}$ respectively. Finally, the third area is weeded at the speed of $2.5 \mathrm{kmmh}$. The demerit obtained is shown in Table 2, and the comparison before and after weeding is shown in Fig. 9

The statistics of weeding test 7 days and 14 days after transplanting respectively are shown in Fig. 10 and 11. According to the two weeding results, when the agricultural weeding robot works at the speed of $1 \mathrm{kmmh}$, the injury rate is the lowest, which is $0.77 \%$; when the agricultural weeding robot works at the speed of $2.5 \mathrm{kmmh}$, the injury rate is the highest, which is $5.08 \%$, and the comprehensive average seedling injury rate is less than $3.4 \%$. The experimental results show that: the robot under the control of a visual servo system can stably and accurately complete the task, and meet the relevant requirements of weeding. Analysis of the difference of seedling injury rate after 7 days and 14 days after transplantation: on the 7th day, because the transplanting time is too short, the seedlings only grow 4-5 small leaves, so the robot vision system is not easy to distinguish it from weeds, so the damage rate of seedlings is higher. However, after 14 days, the growth of the seedlings is greatly improved compared with that of 7 days, which is easier to distinguish from weeds, so the damage rate is lower.

Due to the change in the distance between plants, the speed of the robot will also change. If the speed is too fast, the rotary hoe may fly the uneven soil on the ground, resulting in accidental injury to seedlings. Agricultural robot also has other problems, such as the time-consuming problem of servo 
Table 2. Statistics of weeding test on 14 days after transplanting

\begin{tabular}{|c|c|c|c|c|}
\hline Test lot No & Travel speed kmmh & $\begin{array}{c}\text { Total number of } \\
\text { seedlings }\end{array}$ & $\begin{array}{c}\text { Number of injured } \\
\text { seedlings }\end{array}$ & Injury rate\% \\
\hline $1-1$ & 0.8 & 139 & 2 & 1.44 \\
\hline $1-2$ & 1 & 130 & 1 & 0.77 \\
\hline $1-3$ & 1.4 & 135 & 3 & 2.22 \\
\hline $2-1$ & 1.8 & 133 & 3 & 2.26 \\
\hline $2-2$ & 2 & 138 & 6 & 3.47 \\
\hline $2-3$ & 2.2 & 144 & 5 & 5.08 \\
\hline 3 & 2.5 & 413 & 21 & 2.79 \\
\hline
\end{tabular}

Figure 9. Comparison of weeding trials

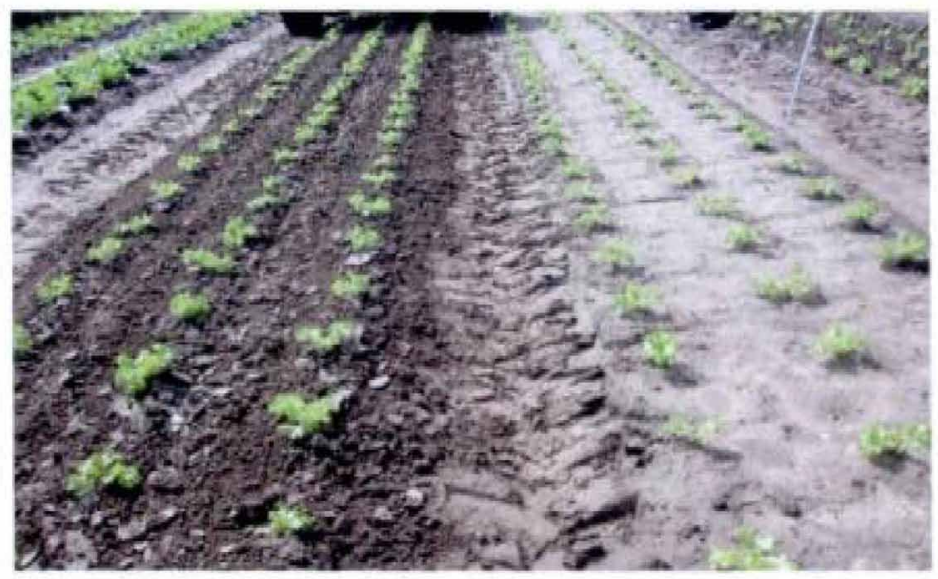

(a)Have weeding

(b)No weeding

Figure 10. Statistics of weeding experiment (7 days after transplanting)

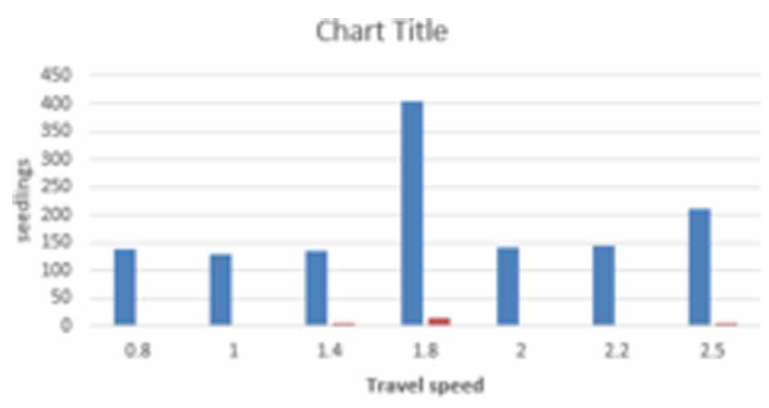

n Total number of seedings . Number of injured seeding 
Figure 11. Statistics of weeding test (14 days after transplanting)

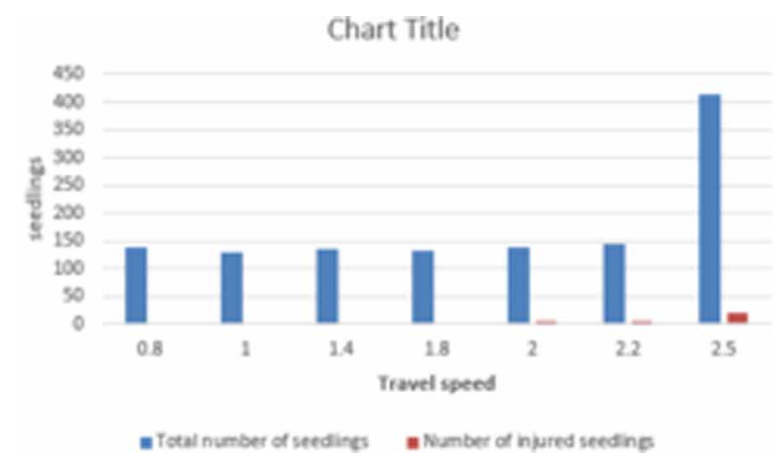

monitoring system detection and calculation, and the slow response problem, tire sideslip movement and other phenomena also emerge one by one when the robot works at high speed.

\section{CONCLUSION}

A vision system of an agricultural robot in the natural environment is proposed in this paper. The two typical environments: farmland and orchard are taken for the analysis. The weeding between farmland crops and orchard production monitoring and prediction tasks, the target information recognition approach and visual servo decision-making are proposed and explained. The proposed system has the following advantages: to reduce the influence of branches and leaves occlusion, the best orientation of active vision, the fixed visual servo of the robot, weeding, background segmentation, target recognition and positioning, and the construction of vision system.

The results obtained from proposed system show that the rate of seedling injury is directly proportional to the walking speed of the robot. It is observed that when the agricultural weeding robot works at the speed of $2.5 \mathrm{kmmh}$, the highest injury rate is $5.08 \%$, and the comprehensive average injury rate is less than $3.4 \%$, which meets the relevant requirements of weeding. Further, the real time implementation based application can be taken in the future endeavor for this system. 


\section{REFERENCES}

Chanak, P., \& Banerjee, I. (2020). Internet of Things-enabled Smart Villages: Recent Advances and Challenges. IEEE Consumer Electronics Magazine.

Chauhan, P., Mandoria, H. L., Negi, A., \& Rajput, R. S. (2020) Plant Diseases Concept in Smart Agriculture Using Deep Learning. In Smart Agricultural Services Using Deep Learning, Big Data, and IoT (pp. 139-153). IGI Global.

De-An, Z., Jidong, L., Wei, J., Ying, Z., \& Yu, C. (2011). Design and control of an apple harvesting robot. Biosystems Engineering, 110(2), 112-122. doi:10.1016/j.biosystemseng.2011.07.005

Devetak, S. M., Susa, V. B., Pavlovic, B. Z., Slavkovic, R. V., \& Karovic, S. M. (2019). Performance Analysis of One Model of Communication and Information System in Military Operation. Defence Science Journal, 69(3), 290-297. doi:10.14429/dsj.69.12932

Hasan, R. I., Yusuf, S. M., \& Alzubaidi, L. (2020). Review of the State of the Art of Deep Learning for Plant Diseases: A Broad Analysis and Discussion. Plants, 9(10), 1302. doi:10.3390/plants9101302 PMID:33019765

Hu, W. J., Fan, J., Du, Y. X., Li, B. S., Xiong, N., \& Bekkering, E. (2020). MDFC-ResNet: An Agricultural IoT System to Accurately Recognize Crop Diseases. IEEE Access: Practical Innovations, Open Solutions, 8 , 115287-115298. doi:10.1109/ACCESS.2020.3001237

Huirong, X., Zunzhong, Y., \& Yibin, Y. (2005). Identification of citrus fruit in a tree canopy using color information. Nongye Gongcheng Xuebao (Beijing), 5.

Jani, M., Garg, P., \& Gupta, A. (2019). Performance Analysis of a Mixed Cooperative PLC-VLC System for Indoor Communication Systems. IEEE Systems Journal, 14(1), 469-476. doi:10.1109/JSYST.2019.2911717

Khanam, R., Haseen, Z., Rahman, N., \& Singh, J. (2019). Performance Analysis of Iris Recognition System. In Data and Communication Networks (pp. 159-171). Springer. doi:10.1007/978-981-13-2254-9_14

Kour, V. P., \& Arora, S. (2020). Recent Developments of the Internet of Things in Agriculture: A Survey. IEEE Access: Practical Innovations, Open Solutions, 8, 129924-129957. doi:10.1109/ACCESS.2020.3009298

Peppes, N. (2020). The role of drones as an enabler for the 4th agricultural revolution. Current Research in Agricultural Sciences, 7(2), 40-51. doi:10.18488/journal.68.2020.72.40.51

Purnama, D. E., Wijaya, A. F., \& Cahyono, A. D. (2020). Performance Analysis Of Information System/ Information Technology using COBIT 4.1. Journal of Information Systems and Informatics, 2(1), 105-113. doi:10.33557/journalisi.v2i1.48

Rathee, G., Sharma, A., Iqbal, R., Aloqaily, M., Jaglan, N., \& Kumar, R. (2019). A blockchain framework for securing connected and autonomous vehicles. Sensors (Basel), 19(14), 3165. doi:10.3390/s19143165 PMID:31323870

Rathee, G., Sharma, A., Kumar, R., Ahmad, F., \& Iqbal, R. (2020). A trust management scheme to secure mobile information centric networks. Computer Communications, 151, 66-75. doi:10.1016/j.comcom.2019.12.024

Rathee, G., Sharma, A., Kumar, R., \& Iqbal, R. (2019). A secure communicating things network framework for industrial IoT using blockchain technology. Ad Hoc Networks, 94, 101933. doi:10.1016/j.adhoc.2019.101933

Shariski, F. H., Priandana, K., \& Wahjuni, S. (2020, February). Performance Analysis of Self-Organizing Map Method for Wheeled Robot Control System. In 2020 International Conference on Smart Technology and Applications (ICoSTA) (pp. 1-5). IEEE.

Sharma, A., Kumar, R., \& Singh, P. K. (2019). SLA Constraint Quickest Path Problem for Data Transmission Services in Capacitated Networks. International Journal of Performability Engineering, 15(4). Advance online publication. doi:10.23940/ijpe.19.04.p1.10611072

Tang, Y. C., Wang, C., Luo, L., \& Zou, X. (2020). Recognition and localization methods for vision-based fruit picking robots: A review. Frontiers in Plant Science, 11, 510. doi:10.3389/fpls.2020.00510 PMID:32508853

Tanigaki, K., Fujiura, T., Akase, A., \& Imagawa, J. (2008). Cherry-harvesting robot. Computers and Electronics in Agriculture, 63(1), 65-72. doi:10.1016/j.compag.2008.01.018 
Thalengala, A., Shama, K., \& Mangalore, M. (2018). Performance Analysis of Isolated Speech Recognition System Using Kannada Speech Database. Pertanika Journal of Science \& Technology, 26(4).

Yang, J., Wang, C., Jiang, B., Song, H., \& Meng, Q. (2020). Visual perception enabled industry intelligence: State of the art, challenges and prospects. IEEE Transactions on Industrial Informatics.

Yanying, F., Zimin, Z., Guanping, C., Biqing, L., \& University, H. (2019). The application of visual sensor in the recognition system of the target fruit of the picking robot. Nong-ji-hua Yanjiu.

Yiman, W. (2018). Design of vision system for mobile picking robot target recognition based on dsp. Nong-jihua Yanjiu.

Zhang, C., \& Chen, Y. (2020). A Review of Research Relevant to the Emerging Industry Trends: Industry 4.0, IoT, Blockchain, and Business Analytics. Journal of Industrial Integration and Management, 5(01), 165-180. doi:10.1142/S2424862219500192

Zhao, Y., Gong, L., Huang, Y., \& Liu, C. (2016). Robust tomato recognition for robotic harvesting using feature images fusion. Sensors (Basel), 16(2), 173. doi:10.3390/s16020173 PMID:26840313

Zhao, Y., Liu, L., Xie, C., Wang, R., Wang, F., Bu, Y., \& Zhang, S. (2020). An effective automatic system deployed in agricultural Internet of Things using Multi-Context Fusion Network towards crop disease recognition in the wild. Applied Soft Computing, 89, 106128. doi:10.1016/j.asoc.2020.106128

Yun Ji is associated with Chongqing Vocational College of electronic engineering, Chongqing 401331. Yun has expertise in agriculture, robotics, and optimization. Currently, Yun is working on various national and international projects. Currently, Yun is associated with Chongqing Vocational College of electronic engineering, Chongqing 401331. Yun has expertise in agriculture, robotics, and optimization. Currently, Yun is working on various national and international projects.

Rajeev Kumar is working, as an Assistant Professor, at Chitkara University Institute of Engineering and Technology, Chitkara University, Punjab, India. He received his B. Tech. and M. Tech. Degrees in Electronics and Communication Engineering from Kurukshetra University, Kurukshetra, India, in 2008 and 2010 respectively and also completed his Ph.D. degree in Electronics Engineering from Banasthali University, Rajasthan, India, in 2017. His research interests include almost aspects of Antenna Design with special emphasis on Frequency reconfigurable Antenna, Ultra wide-band Antenna, Multiband Antenna and Slot Antenna. During his research, He has published 27 research papers in various reputed publishing houses like IEEE, Wiley, AEU, Hindawi, PIERS and many more. Dr. Kumar has been served as a reviewer for many Journals like Wiley, Elsevier, and PIERS, etc. and also worked as a reviewer for ICICS-2016 for the track of Antenna Design.

Daljeet Singh received the B.Tech (Hons.) and M.Tech. in electronics and communication engineering from Lovely Professional University, India in 2011 and 2013 respectively, and the Ph.D. degree in electronics and communication engineering from Thapar Institute of Engineering and Technology, India in 2019. He is currently working as an Assistant Professor at Lovely Professional University, India. His research interests include $5 \mathrm{G}$ and Future Communication systems, channel modeling, Massive MIMO, and multicarrier systems.

Maninder Singh was born in Punjab, India, in 1980. He received the B.E. and M.E degree in Electronics and Communication Engineering from Punjab Technical University, Jalandhar, India, and Ph.D. degrees in Electronics Technology from Guru Nanak Dev University, Amritsar, India in 2016. In 2017, he joined Simon Fraser University, Burnaby, Canada as Post-Doc research scholar. Since January 2018, he has been working in Rayat-Bahra University, Mohali, India. His current research interests include Machine Learning algorithms, Routing and Wavelength assignment models, reliable data communication and digital circuits. Dr. Singh is a Life Member of the Indian Society for Technical Education (ISTE) and Punjab Academy of Sciences. He has published more than 25 research papers in reputed journals and IEEE conferences. 